2. Yuta Shibamoto, Akifumi Miyakawa, et al. (2015). Radiobiology of SBRT: 11-25.

3. U.S. Deparment of heath anh human services (2017), Common Terminology Criteria for Adverse Event ( CTCAE) version 5.0: U.S.

4. Eisenhauer E.A, Therasse P., J. Bogaerts, et al.(2009). New response evaluation criteria in solid tumours: revised RECIST guideline (version 1.1). Eur J Cancer, 45(2): 228-47

5. Bustamante J., Llovet JM, et al.(1999). Natural history of untreated nonsurgical hepatocellular carcinoma: rationale for the design and evaluation of therapeutic traials Hepatology, 29(62): 7

6. Choi H.S., Kang K. M., et al. (2021). Effectiveness of stereotactic body radiotherapy for portal vein tumor thrombosis in patients with hepatocellular carcinoma and underlying chronic liver disease. Asia Pac J Clin Oncol, 17(3): 209-215.

7. Shui Y., W. Yu, et al.(2018). Stereotactic body radiotherapy based treatment for hepatocellular carcinoma with extensive portal vein tumor thrombosis. Radiat Oncol, 13(1): 188

8. Li Zhang, Mian Xi, et al. (2013). Effectiveness of Stereotactic Body Radiotherapy for Hepatocellular Carcinoma with Portal Vein and/or Inferior Vena Cava Tumor Thrombosis. PLoS One, 8(5): e63864

9. Li X., Ye Z., et al.(2021). Predictive factors for survival following stereotactic body radiotherapy for hepatocellular carcinoma with portal vein tumour thrombosis and construction of a nomogram. BMC Cancer, 21(1): 701

\title{
THỰC TRẠG LO ÂU, TRẦ CẢM Ở HỌC SINH LỚP 12 TẠI 2 TRƯỜNG TRUNG HỌC PHỔ THÔNG CỦA THÀNH PHỐ THÁI BÌNH NĂM 2020
}

\section{TÓM TẮT}

Nghiên cứu mô tả cắt ngang nhằm mô tả thực trang lo âu, trầm cảm của học sinh và một số yếu tố liền quan ở đối tượng học sinh lớp 12 tại 2 trường THPT của thành phố Thái Bình năm 2020. Nghiên cứu thu thập thông tin qua phát vấn bộ câu hỏi sử dụng bộ công cu DASS-21. Kết quả cho thấy tỷ lệ học sinh có biểu hiện lo âu là $24 \%$, trầm cảm là $60 \%$. Về mức độ, tỷ lệ lo âu từ nhẹ, vừa, nặng, rất nặng lần lượt là $10,5 \% ; 6,8 \% ; 4,5 \% ; 2,2 \%$. Tỷ lệ trầm cảm từ nhẹ, vưua, nănng, rất nắng lần lượt là $13,3 \% ; 24,2 \% ; 10,3 \%$; $12,2 \%$. Sự thiếu quan tâm của bố mẹ, thây cô làm tăng nguy cơ mắc trầm cảm, lo âu ở học sinh. Ngoài ra thường xuyên bị áp lực thi, kiểm tra cũng là yếu tố làm tăng nguy cơ mắc trầm cảm. Các yếu tố hài lòng về mối quan hệ bạn bè, và tình trạng hôn nhân của bố me có liên quan tới tình trạng lo âu của đối tượng nghiên cứu. Tăng cường sự quan tâm của gia đỉnh, bạn bè, thây cô và nhà trường trong việc sắp xếp thời gian học sẽ góp phần làm giảm tỷ lệ mắc bệnh ở học sinh.

Tứ khóa: lo âu, trầm cảm, học sinh lớp 12, Thái Bình.

\section{SUMMARY}

CURRENT SITUATION OF ANXIETY, DEPRESSION, AND SOME RELATED FACTORS AMONG 12 ${ }^{\text {TH }}$ GRADE STUDENTS OF TWO HIGH SCHOOL IN THAI BINH, 2020

A cross-sectional descriptive study was conducted to identify the rate of anxiety, depression and some related factors to anxiety, depression in 12th grade

*Trường Đại học Y Dược Thái Bình

Chiu trách nhiệm chính: Ngô Văn Mạnh

Email: manhsdh@gmail.com

Ngày nhận bài: 21.6.2021

Ngày phản biên khoa họ: 18.8.2021

Ngày duyệt bài: 24.8.2021
Ngô Văn Mạnh*, Phạm Thị Hương Ly*

students at 2 high school in Thai Binh city. The information was collected through a set of questionnaires using the DASS- 21 toolkit. The results show that the percentage of students with anxiety was $24 \%$, depression was $60 \%$. About level, the rate of anxiety from mild, moderate, severe, extremely severe was $10.5 \% ; 6.8 \% ; 4.5 \% ; 2.2 \%$ respectively. The rate of depression from mild, moderate, severe, extremely severe was 13.3\%; 24.2\%; $10.3 \% ; 12.2 \%$ respectively. The lack of attention from parents and teachers increases the risk of depression and anxiety in students. In addition, frequent exam pressure is also a factor that increases the risk of depression. Satisfaction factors with friends, and parents' marital status are related to the anxiety status of the study subjects. Increasing the concerns of families, friends, teachers and schools will contribute to reduce the proportion of disease among high school students.

Keywords; Anxiety; Depression; 12th grade students; Thai Binh.

\section{I. ĐĂT VẤN ĐỀ}

Cùng với sư phát triển nhanh chóng và đầy biến động của nền kinh tế - xã hội đã đem đến cho quá trình sống, học tập và rèn luyện của học sinh ngày càng nhiều cơ hôi nhưng cũng chứa đựng nhiêu yếu tố bất lợi đối với sự phát triển nhân cách thế hệ trẻ. Đặc biệt, với lứa tuổi trung học phổ thông (THPT) nói chung và học sinh lớp 12 nói riêng, thời đại 4.0 có tác động rất lớn đến sức khỏe tâm thần của các em. Hiên nay học sinh mắc các rối loạn tâm lý chiếm tỉ lệ khá cao và đang nhận được rất nhiều sự quan tâm của toàn xã hội.

Theo Tổ chức $Y$ tế thế giới, $20 \%$ trẻ em và thanh thiếu niên trên thế giới được tiên lượng là có rối loạn hay vấn đề về tâm thần trong đó, 
khoảng $1 / 2$ các rối loạn tâm thần bắt đầu từ trước lứa tuổi 14 [1] Tại Thổ Nhĩ Kỳ nghiên cứu trên 1482 hoc sinh từ lớp bốn đến lớp tám kết quả cho thây tỷ lệ là $4,2 \%$ có rối loạn trầm cảm, 1,55\% rối loạn trầm cảm nặng nề [2] hay tại Đông Bắc Trung Quốc tỷ lệ mắc rối loạn DSM-IV chung ở trẻ em và thanh thiếu niên là 9,49\%, trong đó có $15,2 \%$ có hai hoặc nhiều rối loạn [3]. Tại Việt Nam, số lượng trẻ em trong độ tuổi học sinh mắc các rối loạn stress, lo âu và trâm cảm có xu hướng tăng lển trong những năm gần đây. Như tại trường trung học phổ thông (THPT) chuyên Quảng Bình tỷ lệ rối loạn lo âu ở học sinh chiếm 21,6\%[4], hay tỉ lệ học sinh THPT huyện Chương Mỹ - Thành phố Hà Nội mắc lo âu là 84,17\% [5], tỉ lệ các trẻ học sinh trung học cơ sở quận Hoàng Mai Hà Nội gặp phải vấn đề trầm cảm là không nhỏ dao động từ 6,57 đến 7,58\%[6].

Thái Bình là một tỉnh thuộc Đồng bằng Bắc bộ, tổng số có 39 trường trung học phổ thông trên đia bàn toàn tỉnh với hơn 17.000 học sinh khối lớp 12, khối lớp cuối cấp có nhiêu yếu tố dẫn tới các rối loạn tâm lý. Tuy nhiên, hiện chưa có các nghiên cứu về lo âu, trầm cảm trên đối tượng này tại tỉnh Thái Bình. Với lý do đó chúng tôi tiến hành nghiên cứu này với mục tiêu mô tả tỷ lệ lo âu, trầm cảm và xác định một số yếu tố liên quan ở học sinh lớp 12.

\section{II. ĐỐI TƯỚNG VÀ PHƯƠNG PHÁP NGHIÊN CỨU}

2.1 Đối tượng nghiên cứu. Đối tương nghiên cứu là học sinh khối lớp 12 tại 2 trường Trung học phổ thông Lê Quý Đôn và trường Trung học phổ thông Nguyễn Đức Cảnh,

Tiêu chuân lựa chọn: học sinh tại trường Trung học phổ thông Lê Quý Đôn và trường Trung học phổ thông Nguyễn Đức Cảnh, đồng ý tham gia phỏng vấn, có mặt tại lớp trong thời điểm phỏng vấn, được sự đồng ý tham gia phỏng vấn của phụ huynh.

Tiêu chuân loại trừ: Không hợp tác, trả lời không đủ số liệu trong bảng câu hỏi, có kết luận y tế là rối loạn tâm lý.

2.2 Địa điểm và thời gian nghiên cứu. Nghiên cứu được thực hiện tại 2 trường THPT tại thành phố Thái Bình là: Trường THPT Lê Quý Đôn, Trường THPT Nguyễn Đức Cảnh từ tháng $6 / 2020$ đến tháng $05 / 2021$. Trong đó thời gian thu thập số liệu là từ tháng 10/2020 đến tháng $11 / 2020$.

2.3 Thiết kế nghiên cứu. Nghiên cứu được tiến hành theo phương pháp mô tả cắt ngang.

2.4 Cõ̃ mầu nghiên cứu. Áp dụng công thức tính cõ mẫu so sánh 1 tỷ lệ:

$$
\mathrm{n}=\mathrm{Z}^{2}(1-\alpha / 2) \frac{p(1-p)}{d^{2}}
$$

Trong đó: $\mathrm{n}$ là số học sinh cần nghiên cứu; $\mathrm{p}$ là tỷ lệ rối loạn stress ở học sinh lớp 12 theo nghiên cứu của tác giả Tôn Thất Toàn và cộng sự với $p=0.421$ [7]; d: Độ chính xác tuyệt đối (lấy $\mathrm{d}=0,05)$; a: Chọn mức ý nghĩa thống kê $95 \%$, có $a=0,05$. Thay vào công thức ta có $n=375$. Trên thức tế chúng tôi thu thập được 400 học sinh, mối trường 200 học sinh.

\subsection{Phương pháp chọn mẫu}

- Chọn trường nghiên cứu: chọn chủ đích 2 trường THPT trên đia bàn tỉnh Thái Bình

- Chọn lớp nghiền cứu: lập danh sách các lớp khối 12 và chọn ngẫu nhiên 4 lớp tại mỗi trường theo phương pháp bốc thăm ngẫu nhiên (trung bình mỗi lớp 12 tại các trường nghiên cứu có 50 học sinh, do đó đủ cõ mẫu cho nghiên cứu)

- Chọn học sinh: chọn toàn bộ học sinh tại các lớp được nghiên cứu.

2.6 Biến số trong nghiên cứu. Các biến số về nhân khẩu học của đối tượng gồm: giới tính, học lực, thông tin về gia đình, nhà trường.

Các biến số về thực trạng lo âu, trầm cảm: tỷ lệ học sinh mắc lo âu, trầm cảm; mức độ mắc lo âu và trầm cảm.

2.7 Phương pháp thu thập thông tin. Nghiên cứu của chúng tôi sử dụng phương pháp phát vấn bằng bộ câu hỏi có sẵn và khuyết danh. Bộ câu hỏi gồm các phần:

- Phẩn $A, B$ là các thông tin cá nhân về đối tượng được phỏng vấn và gia đình

- Phần $C, D$ là các câu hỏi liên quan đến các yếu tố ảnh hưởng đến hành vi sức khỏe như các sự kiện căng thẳng trong cuộc sống, yếu tố bản thân, gia đình, học tập và cuộc sống

- Thang đo DASS-21 bao gồm 21 câu trong đó có 14 câu đánh giá lo âu và trâm cảm (Đánh giá lo âu: câu 2, 4, 7, 9, 15, 19, 20; Đánh giá trầm cảm: câu 3, 5, 10,13,16,17,21). Mỗi câu có bốn mức độ trả lời, tương ứng với số điểm là $0,1,2,3$ ( $0=$ không đúng, $1=$ đúng 1 phần/ thỉnh thoảng, $2=$ Đúng nhiều phần/phần lớn thời gian là đúng, $3=$ Hoàn toàn đúng/ hầu hết thời gian là đúng)

2.8 Tiêu chí đánh giá trong nghiên cứu

Đánh giá rối loạn tâm lý theo thang đo DASS-21:

\begin{tabular}{|c|c|c|c|}
\hline \multicolumn{2}{|c|}{ Mức độ } & Trầm cảm & Lo âu \\
\hline \multicolumn{2}{|c|}{ Không mắc } & $0-9$ & $0-7$ \\
\hline \multirow{4}{*}{ Có } & Nhẹ & $10-13$ & $8-9$ \\
\cline { 2 - 4 } mắc & Vừa & $14-20$ & $10-14$ \\
\cline { 2 - 4 } & Nă̆ng & $21-27$ & $15-19$ \\
\cline { 2 - 4 } & Rầt nặng & $\geq 28$ & $\geq 20$ \\
\hline
\end{tabular}


2.9 Phương pháp xử lý số liệu. Số liệu được kiểm tra kỹ trước khi nhập, nhập bằng phần mềm Epidata 3.1 và phân tích bằng SPSS20. Các biến định tính sẽ được mô tả bằng tỷ lệ phần trăm, phân bố tần suất. Các biến định lượng sẽ được mô tả bằng giá trị trung bình, độ lệch chuẩn khi biến có phân phối chuẩn, mô tả bằng trung vị và min- max khi có phân phối không chuẩn. Dùng phép kiểm chi bình phương để so sánh tỷ lệ giữa các nhóm. Mô hình hồi quy logistic đơn biến được sử dụng, các chỉ số $O R$ và $95 \%$ CI sẽ được tính toán để tìm các yếu tố liên quan tới trầm cảm - lo âu của học sinh với mức ý nghĩa $\propto=0,05$.

2.10 Đạo đức trong nghiên cứu. Khảo sát khuyết danh

Nghiên cứu được sự chấp nhân của Ban Giám hiệu các trường. Đồng thời cũng xin ý kiến và nhận được sự đồng ý của hội trưởng hội phụ huynh học sinh của khối lớp 12.

Nghiền cứu này không có tác động trực tiếp nào đến đối tượng nghiên cứu và mọi thồng tin

về đối tượng nghiên cứu, số liệu của cuộc điều tra sẽ được giữ kín để đảm bảo tính riêng tư của các đối tượng nghiên cứu, chỉ phục vụ nghiên cứu.

\section{KẾT QUẢ NGHIÊN CỨU}

Trong số 400 học sinh tham gia, nữ giới nhiều hơn nam giới $(60,3 \%$ so với $39,7 \%)$; phần lớn đối tượng có học lực nằm trong nhóm khá/giỏi $(95,8 \%)$.

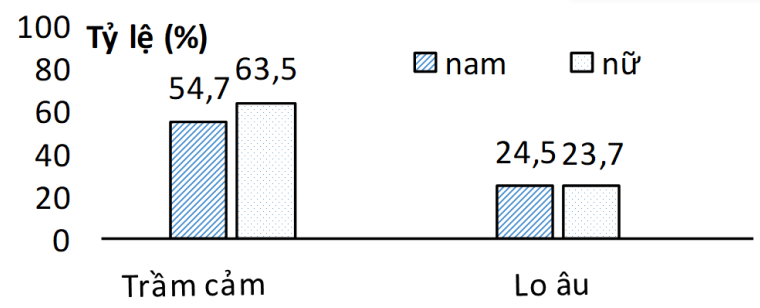

Biển đồ 1. Tỷ lệ trầm cảm - lo âu của học sinh theo giới

Biểu đồ 1 cho thấy tỷ lệ mắc trầm cảm, lo âu phân bố tương đối đều ở hai giới.

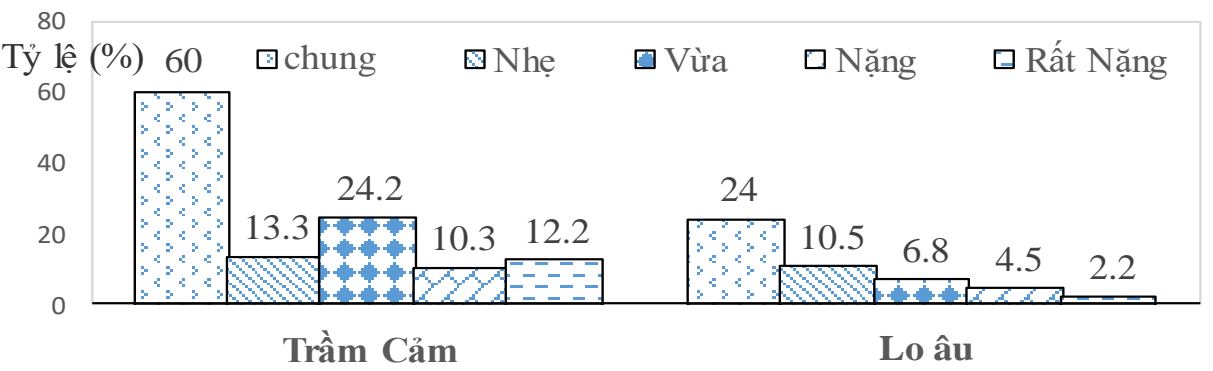

Biên đồ 2. Tỷ lê và sự phân bố mức độ trâm cảm - lo âu của học sinh

Biểu đồ 2 cho thấy tỷ lệ học sinh bị trầm cảm cao hơn so với bị lo âu (60\% so $24 \%)$. Trầm cảm mức độ vừa chiếm tỷ lệ cao nhất trong các mức độ trầm cảm $(24,2 \%)$. Trầm cảm nhẹ và nặng chiếm lần lượt là $13,3 \%$ và $10,3 \%$, tỷ lệ trầm cảm rất nặng khá cao $12,2 \%$. Lo âu mức độ nhẹ chiếm tỷ lệ cao nhất trong các mức độ lo âu (10,5\%). Tỷ lệ lo âu vừa và nặng lần lượt là $6,8 \%$ và $4,5 \%$; lo âu rất nặng chỉ chiếm 2,2\%.

Bảng 1: Các yêu tố liên quan đến lo âu ở học sinh lớp 12

\begin{tabular}{|c|c|c|c|c|}
\hline \multirow{2}{*}{\multicolumn{2}{|c|}{ Biến }} & \multicolumn{3}{|c|}{ Lo âu } \\
\hline & & n (\%) & OR & 95\%CI \\
\hline \multirow{2}{*}{ Giới } & Nam & $39(24,5)$ & 1 & \\
\hline & Nữ & $57(23,7)$ & 0,95 & $0,60-1,52$ \\
\hline \multirow[b]{2}{*}{ Học lực } & Trung bình/Kém & $7(41,2)$ & 1 & \\
\hline & Giỏi/Khá & $89(23,2)$ & 0,43 & $0,16-1,17$ \\
\hline \multirow{2}{*}{$\begin{array}{c}\text { Tình trạng hôn nhân của bố } \\
\text { mẹ }\end{array}$} & Sống chung & $81(22,6)$ & 1 & \\
\hline & Ly hôn & $15(35,7)$ & 1,90 & $1,01-3,76$ \\
\hline \multirow{3}{*}{ Sự quan tâm của bố mẹ } & Bình thường & $46(39,0)$ & 1 & \\
\hline & Tốt & $49(17,6)$ & 0,33 & $0,20-0,55$ \\
\hline & Không tốt & $1(33,3)$ & 0,78 & $0,07-8,97$ \\
\hline \multirow{2}{*}{ Áp lực thi cử, kiểm tra } & Không bao giờ & $3(18,8)$ & 1 & \\
\hline & Hiếm khi & $11(26,2)$ & 1,54 & $0,36-6,54$ \\
\hline
\end{tabular}




\begin{tabular}{|c|c|c|c|c|}
\hline \multirow{3}{*}{ Sự quan tâm của thầy cô } & Thỉnh thoảng & $34(17,8)$ & 0,94 & $0,25-3,49$ \\
\cline { 2 - 5 } & Thường xuyên & $48(31,8)$ & 2,02 & $0,55-7,48$ \\
\hline & Thường xuyên & $25(17,9)$ & 1 & \\
\cline { 2 - 5 } & Thỉnh thoảng & $42(24,9)$ & 1,52 & $0,87-2,66$ \\
\cline { 2 - 5 } & Hiếm khi & $22(34,9)$ & $\mathbf{2 , 4 1}$ & $\mathbf{1 , 2 1 - 4 , 8 8}$ \\
\cline { 2 - 5 } & Không bao giờ & $7(25,9)$ & 1,61 & $0,61-4,24$ \\
\hline \multirow{3}{*}{$\begin{array}{c}\text { Mức độ hài lòng với mối } \\
\text { quan hệ bạn bè }\end{array}$} & Bình thường & $62(33)$ & 1 & \\
\cline { 2 - 5 } & Hài lòng & $27(14,5)$ & $\mathbf{0 , 3 4}$ & $\mathbf{0 , 2 0 - 0 , 5 8}$ \\
\cline { 2 - 5 } & Không hài lòng & $7(26,9)$ & 0,75 & $0,30-1,88$ \\
\hline
\end{tabular}

Bảng 1 cho thấy có mối liên quan giữa tình trạng hôn nhân của bố mẹ, sự quan tâm của bố mẹ, sự quan tâm của thầy cô và mức độ hài lòng với mối quan hệ bạn bè với tình trạng lo âu của đối tượng nghiên cứu. Trong đó đối tượng có bố mẹ ly hôn có nguy cớ lo âu cao gấp 1,90 lần so với bố mẹ vần chung sống; học sinh cảm thấy hài lòng về mối quan hệ bạn bè có nguy cơ mắc lo lắng chỉ bẳng 0,34 lần so với mức độ bình thường $(\mathrm{OR}=0,34 ; 95 \% \mathrm{CI}: 0,20-0,58)$. Bên cạnh đó đối tượng hiếm khi nhận được sự quan tâm của các thầy cô có nguy cơ mắc lo âu cao gấp 2,41 lần so với người thường xuyển được quan tâm.

Bảng 2: Các yếu tố liên quan đến tràm cảm ở học sinh

\begin{tabular}{|c|c|c|c|c|}
\hline \multirow{2}{*}{\multicolumn{2}{|c|}{ Biến }} & \multicolumn{3}{|c|}{ Trầm cảm } \\
\hline & & n (\%) & OR & 95\% CI \\
\hline \multirow{2}{*}{ Giới } & Nam & $87(54,7)$ & 1 & \\
\hline & Nữ & $153(63,5)$ & 1,44 & $0,96-2,17$ \\
\hline \multirow{2}{*}{ Học lực } & Trung bình/Kém & $10(58,2)$ & 1 & \\
\hline & Giỏi/Khá & $230(60,1)$ & 1,05 & $0,39-2,83$ \\
\hline \multirow{2}{*}{$\begin{array}{l}\text { Tình trang hôn } \\
\text { nhân của bố me }\end{array}$} & Sống chung & $213(59,5)$ & 1 & \\
\hline & Ly hôn & $27(64,3)$ & 1,23 & $0,63-2,39$ \\
\hline \multirow{3}{*}{$\begin{array}{l}\text { Sự quan tâm của } \\
\text { bố mẹ }\end{array}$} & Bình thường & $83(70,3)$ & 1 & \\
\hline & Tốt & $156(55,9)$ & 0,53 & $0,33-0,85$ \\
\hline & Không tốt & $1(33,3)$ & 0,21 & $0,02-2,47$ \\
\hline \multirow{4}{*}{$\begin{array}{l}\text { Áp lực thi cử, } \\
\text { kiểm tra }\end{array}$} & Không bao giờ & $7(43,8)$ & 1 & \\
\hline & Hiếm khi & $18(42,9)$ & 0,96 & $0,30-3,11$ \\
\hline & Thinh thoảng & $110(57,6)$ & 1,75 & $0,62-4,91$ \\
\hline & Thường xuyên & $105(69,5)$ & 2,93 & $1,01-8,50$ \\
\hline \multirow{4}{*}{$\begin{array}{c}\text { Sự quan tâm của } \\
\text { thầy cô }\end{array}$} & Thường xuyên & $72(51,4)$ & 1 & \\
\hline & Thinh thoảng & $103(60,9)$ & 1,47 & $0,93-2,32$ \\
\hline & Hiếm khi & $47(73,4)$ & 2,61 & $1,35-5,06$ \\
\hline & Không bao giờ & $18(66,7)$ & 1,89 & $0,79-4,52$ \\
\hline \multirow{3}{*}{$\begin{array}{l}\text { Mức độ hài lòng } \\
\text { với mối quan hệ } \\
\text { bạn bè }\end{array}$} & Bình thường & $116(61,7)$ & 1 & \\
\hline & Hài lòng & $107(57,5)$ & 0,84 & $0,56-1,27$ \\
\hline & Không hài lòng & $17(65,4)$ & 1,17 & $0,50-2,78$ \\
\hline
\end{tabular}

Kết quả bảng trên cho thây có mối liên quan giữa sự quan tâm của bố mẹ, áp lực học tập thi cử và sự quan tâm của thầy cô đến tình trạng trầm cảm. Trong đó học sinh nhận được nhiều sự quan tâm của bố mẹ hơn có nguy cớ trầm cảm chỉ bằng 0,53 lần $(\mathrm{OR}=0,53 ; 95 \% \mathrm{CI}: 0,33-0,85)$ so với đối tượng nhận được sự quan tâm mức độ bình thường. Những học sinh thường xuyên chịu áp lực học tập, thi cử có nguy cơ trầm cảm cao gấp 2,93 lần ( $\mathrm{OR}=2,93 ; 95 \% \mathrm{CI}: 1,01-8,5)$ so với người không chịu áp lực về thi cử, học tập. Bên canh đó đối tượng hiếm khi nhận được sự qua tầm của thấy cô có nguy cơ trầm cảm cao gấp 2,61 lần so với đối tượng thường xuyên nhận được sự quan tâm của thầy cô.

\section{BÀN LUÂ̂N}

Vê thực trạng lo âu, trâm cảm ở học sinh

lớp 12. Kết quả nghiên cứu cho thấy tỷ lệ học sinh mắc rối loạn lo âu là $24 \%$. Tỉ lệ này tương đương với nghiên cứu tỷ lệ rối loạn lo âu ở trẻ em vị thành niên 6 - 17 tuổi ở Uganda là $26,6 \%$ [8], hay nghiên cứu của Nguyễn Thi Huê ở 518 học sinh THPT tỉnh Đắc Lắc với tỷ lệ rối loạn lo âu là $24,13 \%$ [9]. Thấp hơn so với nghiên cứu của tác giả Hồ Hữu Tính và cộng sự năm 2009 với tỷ lệ rối loạn lo âu là 38\% [10], nghiên cứu của Nguyễn Thị Hằng Phương (2008) sử dụng đồng thời cộng cụ nghiên cứu là thang lượng giá DASS-42 và thang lượng giá lo âu Zung cho thấy 
tỷ lệ học sinh có biểu hiện lo âu là 21,66\%. Về mức độ rối loạn lo âu, trong nghiên cứu của chúng tôi tỷ lệ rối loạn lo âu nhẹ là $10,5 \%$, vừa là $6,8 \%$; nặng là $4,5 \%$ và rất nặng là $2,2 \%$. Kết quả này cao hơn so với nghiên cứu của tác giả Nguyễn Thị Huê năm 2013[9] trên học sinh lớp 12 tại một số trường THPT tại địa bàn tỉnh Khánh Hòa. Nghiên cứu của tác giả Danh Thành Tín trên học sinh Trường PTTH tại tỉnh Hậu Giang có kết quả tỷ lẹ lo âu cao hơn nhưng lại có tỷ lệ trầm cảm thấp hơn so với nghiên cứu của chúng tôi với $63,8 \%$ học sinh bị lo âu [7]. Lý do cho sự khác biêt này có thể do thời điểm nghiên cứu khác nhau, áp lực về học tập thi cử và các tác động của xã hội thay đổi rất nhanh nhất là trong thời đại công nghệ số phát triển học sinh tiếp cận với nhiều nguồn văn hóa trong đó có những nguồn thông tin độc hại tác động đến tâm lý và hành vi của học sinh. Ngoài ra có thể do sử dụng bộ công cụ đánh giá khác nhau, một số nghiển cứu đối tượng là học sinh cả 3 khối của trường THPT nên sẽ có các yếu tố tác động đến sức khỏe tâm thần là khác nhau. Bên cạnh đó sự khác biệt về văn hóa, điều kiện và áp lực giáo dục khác nhau giữa các quốc gia dẫn đến sự khác biệt này.

Về tỷ lệ trầm cảm kết quả nghiên cứu ghi nhận tỷ lệ học sinh có biểu hiện trầm cảm là $60,0 \%$, trong đó đa số học sinh trầm cảm mức độ vừa chiếm tỷ lệ $24,2 \%$, mức độ nhe $13,3 \%$, mức độ nặng có tỷ lệ 10,3\%, mức độ rất nặng $12,2 \%$. Kết quả này cao hơn với tỷ lệ trầm cảm học học sinh THPT Vị Xuyên tỉnh Hậu Giang với $42,1 \%$ bị trầm cảm [7], cao hơn so với nghiên cứu của tác giả Nguyễn Thị Minh Ngọc và cộng sự với tỷ lệ trầm cảm là $15,3 \%$. So với nghiên cứu trên thế giới kết quả của chúng tôi thấp hơn so với nghiên cứu của Reem Alharbi và cộng sự với tỷ lệ trầm cảm là $84,0 \%$, cao hơn so với nghiên cứu của Phanthavong $\mathrm{P}$ tại Thủ đô Viêng Chăn, Lào năm 2015 là 24\% học sinh có biểu hiện trầm cảm. Sự khác biệt trển có thể là do công cụ thu thập số liệu, thời gian và thời điểm thu thập số liệu, đối tượng nghiên cứu khác nhau hoặc có thể do điều kiện kinh tế xã hội và phương pháp giáo dục, đào tạo là khác nhau giữa các vùng miền hay các quốc gia khác nhau. Bên cạnh đó, từ các nghiên cứu trên có thể thây rõ các nghiên cứu sử dụng thang đánh giá trầm cảm Beck cho kết quả học sinh có biểu hiện trâm cảm thấp hơn nhiêu so với các nghiên cứu sử dung thang đo DASS-21, có thể lý giải cho sự khác biệt này là mục đích sử dụng thang đo trong các nghiên cứu là khác nhau khi thang đo DASS-21 trong nghiên cứu của chúng tôi đa phần được sử dụng tại cộng đồng với mục đích sàng lọc.

Xét các tỷ lê lo âu, trầm cảm theo giới tính cho thây có sự chênh lệch giữa hai giới. Tỷ lệ trầm cảm ở học sinh nữ nhiêu hơn so với học sinh nam $(65,5 \%$ với $54,7 \%)$ nhưng chưa ghi nhận được mối liên quan có ý nghĩa thống kê. Kết quả này phù hợp với hầu hết các nghiên cứu về sức khỏe tâm thần trước đó như nghiên cứu của Hồ Hữu Tính và Nguyễn Doãn Thành năm 2009 [10]. Nghiên cứu của chúng tôi cũng cho thấy sự khác biệt không nhiều về tỷ lệ trầm cảm và lo âu giữa hai trường, trong đó tỷ lệ trầm cảm ở học sinh trường Lê Quý Đôn cao hơn so với trường Nguyễn Đức Cảnh, tuy nhiên tỷ lệ lo âu lại cho kết quả ngược lại, tuy nhiên sự khác biệt này không có ý nghĩa cho thống kê $(p>0,05)$.

Về các yếu tố liên quan đến lo âu, trâm cảm của học sinh. Đối với tình trạng mắc rối loạn lo âu, kết quả cho thây tình trạng hôn nhân của bố mẹ, sự quan tâm của bố mẹ, của thầy cô và mối quan hệ bạn bè có ảnh hưởng tới nguy cơ mắc rối loạn lo âu ở học sinh. Về yếu tố gia đình những hoc sinh có bố me ly hôn có nguy cơ mắc rối loạn lo âu cao gấp 1,90 lần so với học sinh trong gia đình bố mẹ sống hòa thuận. Kết quả này tương đồng với nghiên cứu tổng quan của Yap MB và cộng sự (2014) thể hiện mối liên quan giữa tình trạng hôn nhân của cha me với rối loạn lo âu của trẻ vị thành niên. Cùng với những tác động khác trong yếu tố gia đình tới rối loan lo âu của học sinh, nghiên cứu của chúng tôi cũng cho thây những trẻ được quan tâm ở mức độ tốt sẽ có nguy cơ mắc rối loạn lo âu chỉ bằng 0,33 lần so với trẻ nhận được sự quan tâm của bố me ở mức độ bình thường. Kết quả này phù hợp với phân tích tổng hợp của 23 nghiên cứu đã tìm thãy mối liên hệ chặt chẽ giữa sự quan tâm của cha me và tình trạng lo âu của học sinh. Tuy nhiên một số bài báo cũng cho thấy viêc kiểm soát ở mức đô độc đoán của cha me cũng là nguyên nhân gây ra những lo lắng cho học sinh Về yếu tố nhà trường sự quan tâm của thầy cô cũng rất quan trọng bởi học sinh hiếm khi nhân được sự quan tâm của thầy cô có nguy cơ mắc rối loạn lo âu cao gấp 2,41 lần (OR=2,41; 95\%CI: $1,21-4,88)$ so với học sinh thường xuyên nhận được sự quan tâm của thây cô giáo. Nghiên cứu của chúng tôi còn cho thây hơc sinh cảm thấy hài lòng về mối quan hệ bạn bè có nguy cơ mắc rối loạn lo âu chỉ bằng 0,34 
lần $(\mathrm{OR}=0,34 ; 95 \% \mathrm{CI}: 0,20-0,58)$ so với học sinh có mức độ hài lòng bình thường. Điều này dễ hiểu bởi bạn bè là đối tượng tiếp xúc thường xuyên của bất kỳ học sinh nào, các tác động tiêu cực sẽ có ảnh hưởng rất lớn đến sức khỏe tâm thần của các em như tình trạng bắt nạt học đường, hay bạo lực học đường, đặc biệt ở lứa tuổi này việc có các mối quan hệ tình cảm cũng sẽ ảnh hưởng lớn đế quyết định, tâm tư, tinh thần của các em.

Đối với tình trạng mắc rối loạn trầm cảm, kết quả phân tích cho thấy sự quan tâm của bố mẹ, thầy cô cũng như áp lực thi cử, kiểm tra có liên quan tới vấn đề này. Những học sinh nhận được quan tâm của bố me ở mức độ tốt có nguy cơ mắc rối loạn trầm cảm chỉ bằng 0,53 lần so với nhóm nhận được sự quan tâm mức độ bình thường $(\mathrm{OR}=0,53 ; \mathrm{p}<0,05)$. Kết quả này tương đồng nghiên cứu tại Hải Phòng với gia đình hiếm khi quan tâm sẽ có nguy cơ mắc trầm cảm cao hơn so với nhóm được quan tâm $(\mathrm{OR}=4,36$; $p<0,01)$. Nhu câu được lắng nghe, được tâm sự của các em học sinh ở giai đoạn này là rất lớn do đó sự quan tẩm của bố mẹ người thân trong gia đình là cực kỳ quan trọng, có thể định hướng đúng tương lai hay kịp thời có những điều chỉnh phù hợp khi các em có những dấu hiệu bất thường về mặt tâm, sinh lý. Ngoài ra không chỉ từ gia đình, sự quan tâm của các thầy cô cũng ảnh hưởng không nhỏ đến sức khỏe tâm thần của học sinh, cũng như là người trực tiếp có những phát hiên hay can thiệp khi học sinh có những thay đổi bất thường về tâm lý. Kết quả nghiên cứu của chúng tôi cho thấy học sinh hiếm khi nhận được sự quan tâm của thầy cô có nguy cơ mắc rồi loạn cao gấp 2,61 lần so với nhóm thường xuyên nhận được sự quan tâm của thây cô $(O R=2,61 ; p<0,01)$, tương đồng với phát hiện của tác giả Danh Thành Tín và cộng sự [7]. Kết quả nghiên cứu của chúng tôi cũng ghi nhận có mối liên quan giữa áp lực thi cử, kiểm tra với rối loạn trầm cảm, trong đó đối tượng thường xuyên bị áp lực có nguy cơ mắc trầm cảm cao gấp 2,93 lần so với đối tượng không có áp lực $(\mathrm{OR}=2,93$; $p<0,05$ ). Kết quả này tương đồng so với các nghiên cứu của Kaur và Sharma tại Ấn Độ. Áp lực về học tập, thi cử đến từ nhiều phía vần là vấn đề phổ biến ảnh hưởng đến sức khỏe tâm thần ở học sinh, đặc biệt ở những học sinh cuối cấp.

\section{KẾT LUẬN}

Tỷ lệ học sinh lớp 12 có biểu hiện trầm cảm là $60 \%$, lo âu là $24 \%$. Về mức độ, tỷ lệ lo âu từ nhẹ, vừa, nặng, rất nặng lần lượt là $10,5 \%$; $6,8 \% ; 4,5 \% ; 2,2 \%$. Tỷ lệ trầm cảm từ nhẹ, vừa, nặng, rất nặng lần lượt là $13,3 \% ; 24,2 \%$; $10,3 \% ; 12,2 \%$. Nghiên cứu có sự khác biệt không nhiều về tỷ lệ trầm cảm và lo âu giữa hai trường cũng như giữa hai giới và không ý nghĩa thống kê $(p>0,05)$. Sự thiếu quan tâm của bố mẹ, thây cô làm tăng nguy cơ mắc trâm cảm, lo âu ở học sinh. Ngoài ra thường xuyên bị áp lực thi, kiểm tra cũng là yếu tố làm tăng nguy cơ mắc trầm cảm. Các yếu tố hài lòng về mối quan hệ bạn bè, và tình trạng hôn nhân của bố mẹ có liển quan tới tình trạng lo âu của đối tượng nghiên cứu.

\section{TÀI LIÊU THAM KHẢO}

1. WHO. Mental health. 2019.

2. Demir T, Karacetin G, Demir DE, Uysal 0. Epidemiology of depression in an urban population of Turkish children and adolescents. Journal of Affective Disorders. 2011;6(13):168-176.

3. Yang Xiaoli JC, Pan Wen, Xu Wenming, Liang Fang, Li Ning, Mu Huijuan, Na Jun,, Lv Ming AX, Yu Chuanyou, Fu Zenguo, Li Lili, Yu Lianzheng, Tong Lijuan, Pan Guowei. Prevalence of Psychiatric Disorders among Children and Adolescents in Northeast China. Prevalence of Psychiatric Disorders in Chinese School Children. 2014;32(12):1-9.

4. Nguyê̂n Thị Phương Hằng. Thực trạng và nguyên nhân gây ra rối loạn lo âu ở học sinh THPT chuyên Quảng Bình. Tạp chí tẩm lý học. 2009;6(123):57-63.

5. Ngô Thị Liên. Thực trạng biểu hiện lo âu của học sinh THPT huyện Chương Mỹ thành phố Hà Nội Luận văn thạc sĩ, Đại học quốc gia, Đại học Giáo duc; 2013.

6. Nguyến Thị Mai. Tìm hiểu thực trạng các biểu hiên trầm cảm của hơ sinh trung hợ cơ sở quận Hoàng Mai, Hà Nội: Luận văn thạc sĩ tâm lý học, Đai học quốc gia Hà Nôi, Đai hoc Giáo duc 2013.

7. Danh Thành Tín, Lê Minh Thuận, Huỳnh Ngọc Thanh. Tỷ lê Stress, lo âu, trầm cảm của hoc sinh trường THPT chuyên Thanh Tỉnh Hậu Giang và các yếu tố liên quan. Tạp chí Y dược Thành phổ Hồ Chí Minh. 2021;25(2):161-167.

8. Abbo C, Kinyanda E, Kizza RB, Levin J, Ndyanabangi $S$, Stein DJ. Prevalence, comorbidity and predictors of anxiety disorders in children and adolescents in rural north-eastern Uganda. Child Adolesc Psychiatry Ment Health. 2013;7(1):21.

9. Nguyễn Thị Huê và Nguyễn Thị Hằng. Ảnh hưởng của khí chấtđến mức độ lo âu ở lứa tuổi học sinh trung học phổ thông. Tạp chí tâm lý học. 2012;3(156): 24-33.

10. Hồ Hữu Tình và Nguyễn Doãn Thành. Thực trang stress lo âu và những liên quan đến lo âu ở học sinh cấp 3 trường THPT Phan Bội Châu, Phan Thiết, Bình Thuận tháng 4-2009. Tạp chí Y học thành phố Hồ Chí Minh. 2010;14(2):180-187. 